This is the 'Author's Accepted Manuscript' version. The final publication is available at Springer via http://dx.doi.org/10.1007/s10804-014-9199-5.

Please cite this article as: Robinson, Oliver C. and Stell, Alexander J. (2014) Laterlife crisis: Towards a holistic model. Journal of Adult Development. doi:10.1007/s10804-014-9199-5

\title{
Later-life crisis: Towards a holistic model
}

Robinson, Oliver C. (first author)

Department of Psychology and Counselling, University of Greenwich, Avery Hill Road, London, SE9 2UG, UK

United Kingdom

o.c.robinson@gre.ac.uk

Tel: +44 (0)2083319630

Fax: +44 (0)2083319160

Stell, Alexander, J. (second author)

School of Psychology,

University of Sussex,

Falmer, BN1 9QH

United Kingdom

a.stell@sussex.ac.uk

Tel: +44 (0)1273 876638

Fax: +44 (0)1273 678058 


\begin{abstract}
Although crisis episodes have been most commonly associated with midlife, research on crisis after midlife is marked by its absence. Here we report findings from a retrospective interview-based study of 21 adults about crises occurring between the ages of 60 and 69 in the first attempt to explore the holistic structure, process and experiential contents of later-life crisis. Basing our analysis on existing models of late-adult development, four key areas of later-life crisis were explored: (1) life events and relationships, (2) self and identity, (3) motivation and goals, and (4) cognition and affect. We were able to define a provisional common holistic process to later-life crisis episodes, shared by all participants, which included multiple loss-inducing stressful life events that provide a cumulative challenge to coping resources, a struggle with ego integrity, increased mortality awareness, and the rescaling of goals, activities and roles in ways that pertain to re-engagement, continuity or disengagement. Findings are discussed in relation to theories of adult development in later life whilst strategies are proposed for future research on this understudied area.
\end{abstract}

\title{
Keywords
}

Crisis, later life, retirement, ego integrity, Third Age, disengagement, qualitative 


\section{Later-life crisis: Towards a holistic model}

In the popular press and academic literature, crisis episodes have been most commonly associated with the forty to fifty age range, via the concept of the midlife crisis (Lachman, 2004; O’Connor \& Wolfe, 1987). Developmental crises in younger adults have now also been recognised, due to the work of Levinson (1986) on the presence of crises in the 'Age 30 Transition', and a more recent programme of research into crisis episodes in the 25 to 35 age group (Robinson \& Smith, 2010; Robinson, Wright \& Smith, 2013). In contrast, there is a marked lack of research dedicated to understanding crisis episodes after midlife. In order to help fill this void, the current study reports the findings of an interview-based study of older adults, which investigated the defining experiences and processes of crisis episodes that occur between the ages of 60 and 69.

\section{Defining crisis episodes in adulthood}

A crisis episode is a period in a person's life that typically lasts a matter of years, during which major transitions and stressors test and occasionally surpass their capacity to cope effectively, correspondingly leading to an atypical level of emotional instability and negativity (Caplan, 1964; Erikson, 1968; Slaikeu, 1990). The instabilities and challenges of a crisis lead to questioning of one's lifestyle, values, goals, and sense of identity, which in turn activates a goal to understand the causes of the crisis and potential resolutions to it (King, 2001). While Erikson (1980) theorised that crisis is a stimulus for developmental growth insofar as it acts to initiate a move to a higher level of equilibrium, research in fact shows that while approximately half of crises are perceived as leading to growth, half lead to no growth or decline (Robinson \& Wright, 2013). It seems that crises are periods of heightened vulnerability and instability that contain the potential for positive and negative outcomes.

Changes that occur during crises episodes are multifaceted, and can be analysed and interpreted at various levels, including (1) life events and relationships, (2) self and identity, (3) motivation and goals, and (4) cognition and affect (Robinson, Wright and Smith, 2013). To study crisis holistically requires theoretical frameworks that inform and aid interpretation 
at all four levels. For the current research, Laslett's concept of the Third Age provided a set of concepts for understanding the level of life events and relationships, while Erikson's theory of ego integrity vs. despair in later life provided the foundation for understanding the level of self and identity. Theories that aided interpretation at the level of motivation and goals were disengagement theory, continuity theory and activity theory, while the cognitiveaffective level was principally interpreted through the lens of socio-emotional selectivity theory. While the aim of the study was to inductively develop a model, it was considered important to situate the model within these broader concepts, models and theories, and thus to give it a clear conceptual location within the lifespan literature. Concepts refer to simple generalities that describe a variety of different phenomena under a single umbrella idea; models describe multiple concepts and the relationships between concepts; theories go further by purporting an explanation for why a phenomenon occurs, or a set of antecedents that show how it comes about.

\section{The Third Age}

A person is thought to be able to enjoy the 'Third Age' of life if they are no longer pressured by full-time work, not constrained by daily parenting responsibilities, have sufficient health to live independently as well as sufficient income to engage in leisure pursuits (Weiss \& Bass, 2002). It is a concept that defines an optimal post-retirement state of freedom and fulfilment (Laslett, 1989). While the concept of retirement pertains specifically to the sphere of work, the Third Age is a broader idea that encapsulates the life spheres of relationship, family, finance, work and health, all of which are assumed to be interdependent.

Despite the positive focus of the Third Age concept, neither retirement from full-time work nor the 'empty nest' transition of children moving out of home are inherently positive transitions; they may bring psychological challenges such as the loss of routine, structure and meaning provided throughout midlife by work and parenting roles (Weiss \& Bass, 2002). The resolution of this loss is known to be achieved with varying degrees of success; some achieve it with ease, while others experience a decline in self-esteem and an enduring sense of loss regarding their previous role of provider, parent or productive worker (Robinson, Demetre \& 
Corney, 2011; Wong \& Earl, 2009). Adding to these challenges, illness also becomes more prevalent in this age group, as does the likelihood of bereavement (Berger, 2011). Based on clinical observation, Marris (2002) stated that crisis in the Third Age is related to the cooccurrence of age-linked stressful life events:

“Often, critical experiences cluster together; illness provokes retirement, retirement provokes a move, the move puts family and old friends at a distance, and in the midst of all this someone dear to us dies. But there may be twenty years of life ahead, or more, and if people are to enjoy a meaningful old age, they have to work through these crises.” (Marris, 2002, p.23)

Depression in this age group is predicted by illness, disability and 'psychosocial adversity' (negative life events), suggesting that understanding the dynamics of crisis episodes may help further to understand mental health in later life (Alexopoulos, 2005).

While the Third Age concept may be relevant for many adults, it does not apply to certain individuals over 60. A proportion of individuals continue full-time work voluntarily into their seventies and even eighties (Ho \& Raymo, 2009; O’Rand, Henretta, \& Krecker, 1992). Furthermore, financial constraints may prevent some adults who would like to retire from doing so. Finally, for parents who have disabled children, some responsibility of care will be present indefinitely, meaning that there is no clear post-parenting period. So while the Third Age provides a useful starting point for the current study, its postulates are conceived as normative but neither culturally nor individually invariant.

\section{Erikson's model of ego development in later life}

Erikson's stage model of ego development posits a particular dialectic as the dominant concern for self and ego-concerns in old age; integrity vs. despair. Integrity manifests in the personal acceptance of the past, present and perceived future of one's own life (Erikson, Erikson \& Kivnick, 1986). Acceptance of the past entails not dwelling excessively on regrets, painful memories or secrets, and resolving any past conflicts with family or friends (Torges, Stewart and Duncan, 2008). Acceptance of the present involves finding satisfaction with how life is rather than how it could be, and thus not mentally struggling against the inevitability of 
one’s current life circumstances (Viney \& Tych, 1985). Acceptance of the future involves finding peace with the prospect of having to scale back activities with age, with asking for help more (Boone James \& Zarrett, 2006), and with the prospect of morbidity and death (Erikson et al., 1986).

At the opposite end of the dialectic, despair is characterised by rumination over past mistakes, and a desire to turn back time to an age when life still held meaning. It brings with it a feeling that one is running out of time, that life is too short and that there is only a finite amount of opportunity to find peace, order and meaning (Erikson, 1968; Erikson, 1980). It results in a fear of mortality and an internal protest at the idea of being an 'old' person (Ryff \& Heincke, 1983). Despair in older adulthood has been related to health issues and sleep disturbances such as insomnia (Wagner, Lorion \& Shipley, 1983).

Ego integrity is perceived by both younger and older adults to increase with age, supporting the view that it is linked to being an older adult (Ryff \& Heincke, 1983). Erikson stated that neither too much integrity nor too much despair is optimally healthy, but rather that a healthy balance between them was preferable. Integrity should be dominant, but if it becomes too dominant, this may lead to an acceptance of one's situation even when that situation is unfair, distressing, demeaning or discomforting (Erikson et al., 1986).

\section{Disengagement, continuity and activity theory}

A half-century long debate has been waged in the field of gerontology about whether a motivational tendency to disengage from roles and goals, to continue with them, or find new ones, is normative and/or optimal for health and wellbeing. Three theories have proposed differing points of view. Disengagement theory proposes that ageing naturally results in a gradual withdrawal from productive social roles as a person becomes aware of the scarcity of time remaining to them, and of their loss in energy and mental capacity (Cumming, Dean, Newell, \& McCaffrey, 1960; Cumming \& Henry, 1961). Continuity theory suggests that healthy ageing requires adaptive strategies to maintain social connections, continue roles that have been adopted earlier in life, or find similar roles to maintain a positive contribution to society (Atchley, 1989). Finally, activity theory claims that adults over 60 will be healthiest 
and happiest when they participate in new challenges, new activities and keep learning, and thus should avoid any socially-induced incentive or personal motivation for disengagement (Havighurst, 1961). These three theories have been criticised for making universal claims about motivational tendencies that are better conceived as a spectrum of alternatives on a continuum of engagement / disengagement (Koren, 2011). In the current study, reactions to later-life crisis in terms of disengagement, continuity or re-engagement were investigated in the light of these theories, and the possibility that these outcomes constitute a motivational spectrum was a formative notion.

\section{Socio-emotional selectivity theory}

As individuals age, they become increasingly conscious of the time left before either death itself, or before other salient endings such as bereavement or having to give up a valued activity. This process can be conceptualised as a shortening of the person's perceived time horizon. Socio-emotional selectivity theory predicts that this affects cognition and emotion in predictable ways: those with shorter time horizons will increasingly invest their time in emotionally meaningful activities and relationships and will think less about acquisition activities (Carstensen, Isaacowitz \& Charles, 1999). This is because the value of acquisition, whether material, intellectual or social, is premised on living long enough to enjoy the later rewards; if one becomes less confident of one's own longevity, the more immediate importance of socio-emotional wellbeing takes precedence. Correspondingly, compared with younger adults, adults over the age of 50 show a greater preference for attending to positive information and positive memories (Mather \& Carstensen, 2003). Social interaction patterns shift away from relationships and friendships that have an instrumental focus, and from maintaining a large social network, towards a more selective focus on emotionally satisfying close relationships (Carstensen \& Mikels, 2005). Therefore, crises that bring with them a greater awareness of mortality, or endings more generally, should also bring a stronger desire to develop a post-crisis lifestyle that is more orientated towards emotional and cognitive positivity than before.

\section{Research aim and questions}


Crisis in later life has been a neglected topic in the academic literature, and this exploratory study explores its holistic structure, process and experiential contents (recollected events, goals, thoughts, emotions), using data gained in retrospective interviews. The aim was to explore crisis by way of these interview narratives, interpreting it 'abductively' through the four conceptual levels described above, and then to derive a provisional holistic model inductively based on generalities across the cases studied. There is precedent for studying the challenges of ageing using narrative interview-based data (Phoenix, Smith \& Sparkes, 2010; Torges, Stewart \& Duncan, 2009; Walaskay, Whitbourne \& Nehrke, 1983), and indeed Erikson's seminal work on this age group was done using interviews and qualitative analysis (Erikson et al., 1986). The current study was guided by two simple open-ended research questions. The first was: What are the defining features of later life crisis, in terms of identity, life events and relationships, motivation and cognition/emotion? The second question was: Is there a definable common process to later life crisis episodes?

\section{Method}

\section{Participants}

\section{Recruitment and sample}

An online questionnaire was distributed via a retirement services website and e-newsletter, and also disseminated through a paid advertisement on a social networking site popular with older adults. Individuals were briefly asked if they had experienced a personal crisis at some point between the ages of 60 and 69. They were given the following open definition of a crisis: “"A crisis episode is a period in adult life that is noticeably more difficult, stressful and unstable than normal, and is an important turning point in life due to changes that occur during it. Crisis episodes typically last for several years, but may be shorter or longer.” 282 UK-based individuals over the age of 60 responded, and 33\% described having a crisis in their sixties. The survey asked if they would be interested in participating in a phone interview about their past crisis, and if so, if they would leave an e-mail address. The 57 individuals who (a) stated that they had had a crisis in their sixties and (b) gave an email address, were then contacted about participation in a phone interview, and offered a $£ 20$ retail 
voucher as an incentive. 25 individuals replied to the request to participate in a phone interview, of which two withdrew prior to the interview, and two were excluded due to the presence of active and enduring mental health problems. The final sample thus comprised 21 persons: 8 men and 13 women, ranging in age (at interview) from 61 to 76 . All were White British or White Irish. Details of their past professions, current age, and age range of the crisis are shown in Table 1. All names were changed. The professions of the sample were diverse, but there was a noticeable absence of manual or unskilled professions.

\section{(Insert Table 1 here)}

\section{Data collection and procedure}

Data were collected using semi-structured interviews that lasted between 45 minutes and 1 hour 15 minutes, conducted over the phone. In-depth interviews such as these provide data about life episodes at all four levels of analysis described in the introduction (Robinson, Smith \& Wright, 2013).

Prior to participating in the interview, a consent form was posted to the individual's home address with a stamped addressed return envelope. The phone interview was arranged upon receipt of the signed consent form. The researcher called the participant's telephone using Skype - the benefits of using Skype are that recording software for Skype calls is free and easily downloaded, and the researcher's hands are free to make notes during the interview if required. Participants had the option of receiving the call on Skype or their landline telephone - 19 out of 21 chose the landline. The benefit of doing the interviews remotely was that the geographical reach across the UK was enhanced, as illustrated by the wide variety of locations across the UK listed in Table 1. This lessens the possibility of a regional or local bias in the data. Another benefit to the phone interview method is that an elderly person may have reservations about inviting a male researcher into their home, for reasons of security, and this problem is circumvented by doing the research over the phone. 
A proportion of the crises that were described started when individuals were still in their late 50s, but this was considered to be acceptable as in all those cases the affective peak of crisis was after the age of 60 . Three of the crises were evaluated to be still on-going by the persons in question, but they were also considered to be acceptable inclusions as they were able to reflect on their experiences at all four levels, and to describe the processes and experiences of crisis with clarity. Although the perceived ongoing presence of the crisis would make reflections on effects less detached and perhaps more biased, the recency of the events for these three means likelihood of retrospection bias.

\section{Analysis}

Analysis followed the qualitative method designed by Robinson and Smith (2010) for the analysis of crisis episodes in adult life. This method incorporates elements of Interpretative Phenomenological Analysis and Miles and Huberman’s Interactive Model, and combines an emphasis on (a) inductive data-led theme-generation, (b) tentative theory-led interpretation of those themes, (c) the use of matrices and tables in analysis to convey different levels of a crisis and (d) visual representation of the temporal flow of the crisis. Here the analysis is used with a nomothetic objective, which means that its aim is the development of an abstract scheme that is generalizable to other instances (Lamiell, 1998). This process of developing general schemes from qualitative data is well articulated by Strauss and Corbin (1998), and Miles and Huberman (1994).

The analysis process commenced with an intensive notation of each individual interview transcript. Each co-author did this for 11 interviews and 10 interviews respectively. Transcript comments were collated and condensed into a list of themes for each participant, and themes were then ordered by (a) the time they occurred before/during/after the crisis, and (b) the four levels of environment/relationships, identity/ego, motivation/action and affect/cognition. By cross-referencing time with the four analytical levels, a matrix of themes was created for each participant, the cells of which acted as higher-order 'superordinate' themes for the lower-order themes extracted from the interview. Quotes from the transcript that supported each theme were entered beneath the participant's matrix. 
After these theme matrices were developed for all 21 cases, the two researchers met for an intensive brainstorming and theme-triangulation session, in which every interview was reviewed and discussed, while themes across all analyses were compared and contrasted. This led to a provisional set of cross-case super-ordinate themes, which were entered into columns of an Excel spreadsheet. Each individual case was then given a row, and representative quotes that illustrated each super-ordinate theme were entered into the cells of the spreadsheet. Following this, to help develop the model itself (see Figure 1), we employed 'relational analysis' - an add-on methodology for exploring relationships between themes and developing diagrams, which involves employing a taxonomy of relational forms to explore possible meaningful links between themes (Robinson, 2011a). ${ }^{\mathrm{i}}$ Finally, a selection of six finalised themes was coded across all 21 participants by both analysts to show the degree of inter-rater agreement. The agreement level was very high, at $92 \%$, suggesting a reliable thematic scheme was developed.

\section{Results}

\section{Level 1 - Life Events and Relationships}

\section{Multiple loss-inducing stressful life events}

The first defining thematic commonality to the crisis episodes was the presence of at least two loss-inducing stressful life events (and as many as five), occurring simultaneously or in short sequence. Table 2 shows the distribution of these event types across the 21 participants in this study. In all cases, one of the stressful events was either a bereavement or a lifethreatening illness (in oneself or a significant other), and in 8 cases both occurred.

Of the 11 participants who referred to a bereavement, 7 of these were of a parent (in one case an uncle who was considered to be a 'second father'), while 4 were of a partner. Other bereavements of friends, siblings, aunts and uncles were also referred to, but always in conjunction with the loss of a partner or parent. Of the instances of illness in self, the following conditions were reported: Diabetes; mental health diagnosis; arthritis/osteoarthritis; back injury; sciatica; cataracts; stroke; obesity and gastric surgery; prostate cancer; surgery on knees or hips; angina; breast cancer; digestive problems and alcoholism. Of the illnesses 
in significant others, the two most frequently mentioned were dementia and cancer, followed by stroke, liver disease, deafness, alcoholism, macular degeneration and depression.

(Insert Table 2 here)

In addition to the illness or bereavement event in each episode, at least one other kind of lossinducing event occurred during each crisis. The most common of these was retiring from fulltime work. While retirement is perceived as a positive event by many, it is also a lossinducing event, for it means the loss of status, the loss of routine and the loss of social networks. For example, one participant said:

“You don’t even know but there are things you lose and what you do lose are your routines, your friends, those sort of things. And that's not good.” (Ted)

Less frequently mentioned losses in crisis were divorce or relationship break-up, and moving residence to a new area. Two individuals reported unusual stressor events that are not included in Table 2: in the case of Anne, a key stressor was the trial and conviction of her son for a claimed act of grievous bodily harm, and the resulting sense of social isolation in her home town that followed. In the case of Ted, a key stressor was being the victim of a series of violent crimes, including both car and house being seriously damaged.

\section{Level 2: Self and Identity}

\section{The struggle for ego-integrity in the face of greater mortality awareness}

Ego integrity is evidenced through a sense of acceptance of the past, the present and perceived future. The events of the later-life crises described provided a major challenge in this regard. The self-questioning that crisis brings leads to rumination of the past, which can be difficult for those who have regrets or perceived mistakes:

"I think that the problem is that I feel like I've made quite a lot of mistakes in my life.

And, when you're older - when you're over sixty - you tend to go back to those mistakes and they really do affect you then”. (Belinda) 
Others find themselves learning how to accept the limitations of their present situation, which may be against their natural disposition to want to change things:

“I’m one of those people that ... I would get things done. If something needed sorting out... I would be able to prevail: 'This is the way that it's going to be.' And now I can't do that: I have to accept that this is how my life is.” (Steven)

Furthermore, there is typically a struggle over self-worth, with positive and negative evaluations in conscious competition with each other:

“Sometimes you think, 'Oh, I’m a really horrible person.' And then you think, 'No, actually I'm not.’ Everybody’s got a horrible side to them.” (Beatrice)

This struggle between integrity and despair progresses over the course of crisis in both positive and negative directions. Those whose crisis trajectory has a positive outcome describe attitudes that show a new-found resilience and integrity, for example:

“...Yes, life is a series of trials that, like it or lump it, you're going to be faced with problems which are going to arise, some of which are going to test you right to the utmost ... So I have another twenty-odd years yet and I fully intend to live it, not just exist. Anybody can exist for a length of time but, why exist when you can live?” (Tony)

On the other hand, those whose crisis has a negative outcome describe their situation in ways that are redolent of Erikson's description of despair, such as the following examples:

“How much more can you take? How much more do you need to take? It's coming to terms, I think, with the reality of what life is now. And it's hard. And what is the reality of life now? Bloody boring. It is. It’s just routine.” (Elizabeth)

“But I haven’t got anything, 'I plan to do this', 'I’m going to replace the greenhouse' or...When I think about things like that, the landscape is quite bleak. There's no reason for me to be here.” (Steven) 
"Interviewer: So, if you could click your fingers and improve things? Respondent: I would go back to when I was about twelve or fourteen...But, then again, you can’t turn the clock back or I'd be first in line to get in the time machine." (Barry)

\section{Level 3: Motivation and Goals}

\section{Motivational reactions to crisis: The disengagement - re-engagement spectrum}

The challenges of crisis involve some temporary disengagement from work, volunteering and/or social activities, as described here by Barbara, in having to care for her husband.

“I couldn’t go to work anymore. I still managed to do some volunteering but very much scaled down so I felt I couldn’t continue to do all the things that I enjoyed doing. [this] meant that I wasn't seeing the people I was used to seeing, people that I know and have the opportunity to chat and catch up with them. I felt I was becoming a bit more isolated I suppose.” (Barbara)

After immediate requirements for disengagement due to life events have abated, longer-term motivational post-crisis reactions range from disengagement and retreat, through measured continuity, to re-engagement with new work, social networks and productive roles. Some, after the temporary disruptions of the crisis, find a brand new goal and meaningful aspiration to orientate life towards, and thus show positive re-engagement. For example:

“I developed new interests and I started doing some voluntary work in a support organisation for people who had had a neurological crisis like a stroke or had been affected with a degenerative condition. From that all sorts of things developed and I almost took on a new profession...” (Brian)

However, occasionally re-engagement is experienced as a forced, negative event, for example Paula is a single woman and did not feel that her financial situation could justify retirement, even though she would actually like to have more time for relaxation.

“It’s been a pretty grim ride ever since I’ve been down here, because I haven’t been able to find the sort of work that I enjoy and it has been sheer grit and bones and dust slog, and I've had to work all the hours God made to make a living.” (Paula) 
Positive disengagement typically comes as a result of a desire after the crisis to take more time to relax and enjoy life, and to change in the direction of being less busy than prior to the crisis. For example:

"I suppose just getting settled in a new house in a new area, seeing more of my grandson, relaxing a bit more, not getting quite so involved in voluntary work round here but doing some things. I suppose, yes, just relaxing more.” (Beatrice)

“It was a strange time for me because I’ve always been busy, I’ve always had a project on the go, and now I was able to sort of sit back, go down to the allotment, enjoy doing a bit of weeding.” (Robert)

In contrast, negative disengagement after the crisis occurs if and when a person feels that there is no way back into productive roles or a more sociable existence, even though they would like that:

“I can’t get a job or a part-time job or something. Well, I can, but not the sort of thing that I wanted....I do have the irritation that, in [city], people knew me...Here, nobody knows what I can do and it’s very hard to get in somewhere.” (Ted)

\section{Level 4: Cognition-emotion}

\section{Loss-linked depressive emotions and cognitions}

All of the events coded in Table 2 - illness, bereavement, retirement, forcible job loss, divorce, relationship break up and moving to a new area - induce a sense of loss in a person's life, whether that is the loss of a loved one, of a sense of mobility and energy, of a role and status, or a supportive friend network. Depressive emotions and cognitive/affective reactions that relate to that sense of loss were a defining affective feature of the crisis episodes. All interviews explicitly referred to various forms of depressive affect, including descriptions of being down, miserable or sad, or feelings of grief, depression, pointlessness, gloominess and meaninglessness. Examples include: 
"Got miserable, upset, was waking up at four in the morning and felt totally got at," (Hilary)

"Yes, I felt down a lot of the time, yes. It’s difficult to stay optimistic when something like that is going on.” (Barbara)

“I felt like somebody who was thrashing around, mentally... that's what it felt like in the head. 'I’m drowning in something and I don’t know quite what it is.'” (Steven)

“I’ve just had five fairly miserable years.” (Ted)

The loss of social contact that often occurs during a crisis, either as a result of retirement, divorce, moving house or caring from an ill loved-one, also leads to a melancholic feeling of aloneness or loneliness. Half the participants described such feelings of loneliness or isolation in direct relation to the social situation that the crisis events had precipitated. For example:

“I couldn’t go out so much and then loneliness started creeping in and I started getting depressed.” (Barry)

“We've always been there [for friends]. But not one of those friends ever picked up the phone and said, 'Hello.' And I think that, for me, was a huge change in my life because it was the 'In times of trouble, a true friend comes to the door as others go out.' And I'm not somebody that bears grudges. [but] I'm not the same with those people anymore." (Anne)

“I think rather than 'lonely’ its lack of company, any company, never mind a kindred spirit. Yes, so actually isolated? It’s the isolation that's so awful.” (Paula)

\section{Thoughts of mortality and reduced time horizon}

The experiences of loss, particularly in the form of life-threatening illness or bereavement, but also in the losses that accompany retirement or divorce, increase attention to the reality of a person's own mortality and the limited duration of life remaining. 13 of the 21 participants explicitly reflected on how the crisis had brought about thoughts of death and the lack of time remaining in life. Examples of this cognitive/affective reaction are described below: 
"It also makes you recognise your own mortality a bit more. The other worry I had was what if anything happened to me, if I become ill or have an accident, who would look after him?” (Barbara)

“you're having to face your own mortality in a way. You think you're invincible when you're younger... And then, suddenly, bang! Your body is letting ... your mind and the things that you want to do, you suddenly find that you can't do because your body's wear and tear - there's wear and tear on your body that you hadn't realised you've got to cope with.” (Jane)

“I felt that my time here was limited. And I felt that I couldn't see getting out of the bars before I died. And that’s not a nice idea.” (Ted)

\section{A provisional holistic model}

\section{(Insert Figure 1 here)}

Figure 1 presents a provisional model of the process of later life crisis that specifies how the aforementioned themes are linked within a dynamic sequence. Phase 1a refers to the presence of multiple stressful life events such as illness, bereavement, retirement, divorce, change of residence or becoming a carer for parent or spouse. We propose that in later-life crisis, these compound stressors occur within a limited period of time and together challenge or overwhelm the person's capacity to cope. Phase $1 \mathrm{~b}$ refers to the presence of depressive emotions and cognitions during this time, including sadness / loss of self-worth / guilt / loneliness / feeling 'down' or 'miserable'. This affective cluster can be thought of as the most salient aspects of cognitive-affective experience that accompany the outer events of Phase 1a; the arrow from 1a to $1 \mathrm{~b}$ reflects the fact that the former was frequently described as influencing the latter. In Phase 2a and 2b, respondents struggle with ego integrity and goals, on a spectrum of difference rather than in a singular way; some respond to the challenges and emotions of Phase 1 by re-engaging with work and productive roles, seeking a renewed sense of meaning in routine and structure, while others - particularly those who experience illness in the crisis - step back and choose a notably less busy and role-focused lifestyle. The commonality here is that, for all persons who go through a later life crisis, the matter of how 
engaged one remains following the episode is a conscious concern and rarely remains consistent with pre-crisis levels. Ego integrity - the serene acceptance of one's past, present and future - is for some increased by the crisis and for others compromised, as feelings of hopelessness, loneliness, despair, impending mortality and meaninglessness become more prominent. This struggle with integrity-despair and engagement-disengagement is followed by Phase 3, characterised here as four typological outcomes created by crossing integrity/despair with engagement/disengagement. Integrity can be evidenced in conjunction with disengaged and engaged responses to crisis, and the same can be said for despair. Some of our participants were still in Phase 2 (Steven, Belinda, Diane), as they were interviewed when they were still directly struggling with the immediacy of emotions and issues that had been precipitated by the crisis. Of those who had reached Phase 3, all could be classified into one of the four outcomes:

1. Engagement / Integrity (renewed role-based activity + growing sense of acceptance) - Harold, Tony, Edward, Hilary, Anne, Jane, Brian

2. Disengagement / Integrity (voluntary lessening of productive activity and roles + an acceptance of such choices) -Jenny, Florence, Robert, Margaret, Beatrice

3. Engagement / Despair (continued role-based activity that is continued out of sense of necessity + lessening sense of acceptance) - Paula, Barbara

4. Disengagement / Despair (removal of self from productive roles + sense of isolation and regret) - Elizabeth, Edith, Barry, Ted

\section{Discussion}

The first research question of the study asked whether there are defining features of later-life crisis - that is, whether certain things are necessary for a later life crisis to manifest. In response to this, we found a number of themes were present in all cases, and are thus candidates for being defining and necessary features. In support of the observations of crisis in the Third Age by Marris (2002), all cases showed the presence of more than one lossinducing stressful life event that challenged coping resources and emotional wellbeing. The second commonality was the presence of depressive affect during the crisis as a direct 
corollary of the loss-inducing events. This reported event-emotion link supports previous research that shows a relationship between loss events and depressive affect (Brown, Harris, \& Hepworth, 1995). The reality of later life crisis challenges the conception of the Third Age popularised by Laslett (1989) as a time of appreciative and hassle-free reflection on the generative outcomes of adult life, and as an aspirational time of increased freedom. While this positive state may be experienced by some, the sampling survey of 282 adults for this study suggests that around a third of British adults have formative periods of adversity in their sixties, often after retirement, which alter identity, lifestyle, goals and relationships. As predicted by socio-emotional selectivity theory, the changes that occur during the crisis all involve endings, which in turn lead to rumination over matters of mortality, and reprioritising of friendships and relationships and time remaining in life is perceived as more constrained than before (Carstensen et al., 1999).

The second research question was focused on whether there is a definable common process to later life crisis episodes. Figure 1 summarises the inter-relation of the themes over time and in so doing provides a response to this research question. The events and emotions of Phase 1 together act as triggers for Phase 2, which is a period of struggle with ego-identity and goals, the eventual outcome of which is modelled in Phase 3. The resulting four-way outcome matrix conveys the point that ego-integrity in this stage of life can be found both through an active re-engagement with the world, or through the volitional acceptance of a more disengaged, less actively ‘busy’ lifestyle. This supports the position of Koren (2011), who also suggested that engagement or disengagement can both be adaptive and optimal in older adults, depending on the social context and physical health of the person concerned.

The notion of positive disengagement is congruent with the concept of gerotranscendence, which describes and explains positive motivations behind disengagement in later life, including a desire to be in the present moment rather than focus on achieving for the future, and to enjoy the present through simple and fulfilling activities rather than productive or pressured roles (Tornstam, 1989). 
In addition, we found that the middle phase of crisis is defined by a struggle between ego integrity-despair. The dynamic interplay between integrity and despair supports other interview-based research that has previously identified an active struggle along this polarity in this age group (Torges et al., 2009). A change in the direction of despair occurs for some during the crisis. Despairing engagement occurs when a person perceives that they cannot wind down their activity levels, often because of duty, commitment or a financial requirement to keep on working, and so must carry on in roles that no longer provide satisfaction. Conversely, despairing disengagement manifests in a melancholy retreat from the world; a loss of roles and social contact that makes depressive and melancholy feelings more likely.

The defining features of later life crisis are different to crisis that occurs earlier in adulthood in certain ways, while also being notably similar in other ways. Similarities include the presence of stressful endings, new beginnings, self-questioning, instability of life structure and emotional upheaval; these occur in crises in early adulthood and midlife too (Levinson, 1986; O’Connor \& Wolfe, 1987). There are also several key differences: Firstly, crisis events earlier in adulthood are defined by the challenges of becoming embedded in adult roles that come to feel ensnaring and engulfing (Robinson et al., 2013), while later life crisis is defined by the challenges and emotional difficulties of losing those roles, as well as feelings of marginalisation and isolation. Secondly, crises in early adulthood rarely involve illness and bereavements (Robinson \& Wright, 2013), while all later life crises in our sample included one or both of these events.

\section{Limitations and Future Research}

The study aimed to inductively develop a new model of crisis in the 60-69 age range. However, in conjunction with this inductive objective, it was considered important to develop the model within a framework of existing meta-theories of ageing and later life development, by 'abductively' interpreting data based on the concepts and theories outlined in the introduction. This 'middle way' between a purely inductive approach of qualitative methods such as Grounded Theory (Strauss \& Corbin, 1998), and the hypothetico-deductive logic of 
content analysis (e.g. Ryff, 1989), is proposed as an innovative solution to developing new theories or models while ensuring the embeddedness of that new model in existing literature. Employing a starting framework for analysis has pros and cons: It means that the data is not encountered inductively and analysis is shaped by orienting constructs, but we are argue that inductive analysis is not possible in reality, for even simply reading words requires a priori concepts. By including the four levels as orientating constructs we help make sure that the analysis answers the questions we have set, but those four 'levels' are the lens through which we view the data, to make sure we are focusing on the right things, and they are open to being challenged or altered throughout.

The use of an online recruitment process for the current study led to a diverse coverage of professions and UK geography within the sample, however it also meant that the sample was biased towards IT-literate older adults, mainly from the middle of the socio-economic scale. The lack of participants from lower income bands may help explain why financial concerns did not emerge as a dominant theme in crisis. Given this socio-economic and ethnic sample bias, further research in demographics and cultures beyond white middle-class older adults is also an essential next step. In order to facilitate replication of the model in further qualitative studies, it is suggested that future researchers employ the model in Figure 1 as an analytical framework for (a) selecting and phrasing questions in interviews, and (b) structuring analysis of the data. In essence, follow-up qualitative studies would be, by definition, more deductive in emphasis than the current study. An essential aspect of further validation would be to explore whether the model is in any way an artefact of the sampling process, and whether individuals gathered from other recruitment sources, cultures, and countries would report crises with a different balance of life events or experiences.

The interview data gathered on later life crisis in this study are retrospective, and are therefore partially the product of the selective recall, narrative structures and culturallyinfluenced scripts of autobiographical memory (Bernsten \& Bohn, 2009; McAdams, 2001; Robinson \& Smith, 2009). Therefore there is a possibility that the model is a model of later life crisis memories, rather than later life crisis per se. To deal with this limitation in the 
future, it would be possible to follow a group of adults longitudinally from the age of 60 through the subsequent decade, gaining quantitative data on life events, relationships, engagement/disengagement, emotional wellbeing and ego integrity at regular intervals. Data from those participants who subsequently report passing through a later life crisis could be analysed using techniques such as latent growth curve analysis to determine whether the model described in Figure 1 is valid prospectively.

The sample for the study is small compared with quantitative samples, however it is important to emphasise that this research is nomothetic in a different way to standard largesample quantitative research, and that this difference both warrants and justifies a smaller sample (Robinson, 2011b). Nomothetic research is aimed at deriving a general model, theory or law that can then be generalised to other cases. Findings in quantitative studies are elicited at the group level (such as a difference between group averages, or a relation between variables across the group) and generalisations are then made about the group as a whole, and may not apply to single individuals within that group. Indeed many individuals may not correspond to the group finding. For example, if a study finds that older adults on average recall more positive memories than younger adults (Carstensen \& Mikels, 2005), it will still be the case that many individual older adults in the sample recall more negative information than younger adults and vice versa. These individual discrepancies are not a problem, for generalisability of such findings is a matter of how likely they are to be replicated in other samples at the level of the group, and as long as the average difference is the same in a follow-up study, generalisation is considered achieved.

In contrast to the above, nomothetic qualitative research such as the current study aims to elicit commonalities across all participants, not merely the majority or the average group tendency (Lamiell, 2003). This means that a relatively small sample can have disproportionate impact, for the likelihood of the same complex set of inter-related themes being found by chance across twenty one participants is very small; assuming that each of the five themes presented in the results had one of two potential outcomes for each participant (present vs. not present), then there is a $\mathrm{p}<0.5$ probability of finding each theme in each case 
by chance. The probability of finding all five themes in one case is $p<0.05 / 5=0.01$. Across 21 participants, this figure would be further divided by 21, meaning an overall probability of $\mathrm{p}<.0005$ of the thematic results being due to chance. This simple calculation serves to highlight how a small sample in qualitative nomothetic research can lead to robust findings.

A further advantage of building models based on commonalities across all cases is that the resulting model, because of its invariant nature, can potentially generalise to describing and explaining individual instances of later life crisis, which is a key concern for all applied psychologists and clinicians, and which is an ever-present difficulty for standard quantitative research that uses group-aggregate analysis (Robinson, 2011b; 2012).

In final summary, this study has established that crisis episodes occur for some adults who are in their sixties, and that these crises have a regular set of features and a definable process that relates theoretically to the challenges of retirement and advancing age. By taking a holistic theoretical and methodological perspective, which integrates multiple levels, a model has been proposed that can provide a basis for further theoretical or applied work with older adults in crisis.

\section{References}

Alexopoulos, G.S. (2005). Depression in the elderly. The Lancet, 365, 1961-70.

Atchley R. C. (1989). A continuity theory of normal aging. The Gerontologist, 29, 183-190. doi 10.1093/geront/29.2.183

Berger, K.S. (2011). The developing person throughout the life span. New York: Worth.

Bernsten, D. \& Bohn, A. (2009). Cultural life scripts and individual life stories. In P. Boyer \& J. Wertsch (Eds.), Memory in Mind and Culture (pp. 62-82). Cambridge: Cambridge University Press.

Brown, G. W., Harris, T. O., \& Hepworth, C. (1995). Loss, humiliation and entrapment among women developing depression: a patient and non-patient comparison. Psychological Medicine, 25, 7-21. doi 10.1017/S003329170002804X

Caplan. G. (1964). Principles of Preventive Psychiatry. New York: Basic Books. 
Carstensen, L.L., Isaacowitz, D.M., \& Charles, S.T. (1999). Taking time seriously: A theory of socioemotional selectivity. American Psychologist, 54, 165-181. doi 10.1037/0003066X.54.3.165

Carstensen, L. L., \& Mikels, J. (2005). At the intersection of emotion and cognition: Aging and the positivity effect. Current Directions in Psychological Science, 14, 117-21. doi 10.1111/j.0963-7214.2005.00348.x

Cumming, E. \& Henry, W. E. (1961). Growing old. New York: Basic Books.

Cumming, E., Dean, L. R., Newell, D. S. \& McCaffrey, I. (1960). Disengagement - A tentative theory of aging. Sociometry, 23, 23-35. doi 10.2307/2786135

Erikson, E. H. (1968). Identity, youth and crisis. New York: Norton.

Erikson, E. H. (1980). Identity and the life cycle. London: W.W.Norton \& Co.

Erikson, E. H., Erikson, J. M., \& Kivnick, H. Q. (1986). Vital involvements in old age. New York: Norton.

Havighurst, R. J. (1961). Successful aging. The Gerontologist, 1, 8-13. doi 10.1093/geront/1.1.8

Ho, J. H. \& Raymo, J. M. (2009). Expectations and realization of joint retirement among dual-worker couples. Research on Aging, 31, 153-79. doi $10.1177 / 0164027508328308$

King, L.A. (2001). The hard road to the good life: The happy, mature person. Journal of Humanistic Psychology, 41, 51-72.

Koren, C. (2011). Continuity and discontinuity: The case of second couplehood in old age. The Gerontologist, 51, 687-698. doi http://dx.doi.org/10.1093/geront/gnr018

Lachman, M.E. (2004). Development in midlife. Annual Review of Psychology, 55, 305-31. doi 10.1146/annurev.psych.55.090902.141521

Lamiell, J.T. (1998). ‘Nomothetic’ and ‘Idiographic’ - Contrasting Windelband’s understanding with contemporary usage. Theory and Psychology, 8, 23-28.

Lamiell, J.T. (2003). Beyond individual and group differences. London: Sage. 
Laslett, P. (1989). A Fresh Map of Life: The Emergence of the Third Age. London: George Weidenfeld \& Nicolson Limited.

Levinson, D.J. (1986). A conception of adult development. American Psychologist, 41, 3-13. Marris, P. (2002). Holding on to meaning through the life cycle. In, R.S.Weiss \& S.A. Bass, (Eds.), Challenges of the Third Age: Meaning and purpose in later life (pp.3-12). New York: Oxford University Press.

Mather, M., \& Carstensen, L. L. (2003). Aging and attentional biases for emotional faces. Psychological Science, 14, 409-15. doi 10.1111/1467-9280.01455

McAdams, D.P. (2001). The psychology of life stories. Review of General Psychology, 5, 100-22. doi 10.1037/1089-2680.5.2.100

Miles, M.B., \& Huberman, A.M. (1994). Qualitative data analysis: An expanded sourcebook. London: Sage.

O’Connor, D.J. \& Wolfe, D.M. (1987). On managing midlife transitions in career and family. Human Relations, 40, 12, 799-816. doi 10.1177/001872678704001202

O’Rand, A. M., Henretta, J. C., \& Krecker, M. L. (1992). Family pathways to retirement. In M. Szinovacz, D. J. Ekerdt and B. H. Vinick (Eds.), Families and Retirement (pp. 81-98). Newbury Park, CA: Sage Publications.

Phoenix, C., Smith, B., \& Sparkes, A. (2010). Narrative analysis in aging studies: A typology for consideration. Journal of Aging Studies, 24, 1-11. doi 10.1016/j.jaging.2008.06.003

Robinson, O.C. (2008). Developmental crisis and the self in early adulthood: A composite qualitative analysis. Doctoral Dissertation, Birkbeck College, London.

Robinson, O.C. (2011a). Relation analysis: an ‘add-on’ technique for aiding data integration in qualitative research. Qualitative Research in Psychology, 8, 197-209. doi 10.1080/14780887.2011.572745

Robinson, O.C. (2011b). The idiographic / nomothetic dichotomy: Tracing historical origins of contemporary confusions. History \& Philosophy of Psychology, 13, 32-39.

Robinson, O.C. (2012). A war of words: the history of the idiographic/nomothetic debate. The Psychologist, 25, 164-167. 
Robinson, O.C., Demetre, J.D., \& Corney, R.H. (2011). The variable experiences of becoming retired and seeking retirement guidance: A qualitative thematic analysis. British Journal of Guidance and Counselling, 39, 239-258. doi $10.1080 / 03069885.2011 .562484$

Robinson, O.C., Wright, G.R.T., \& Smith, J.A. (2013). The holistic phase model of early adult crisis. Journal of Adult Development. 20, 27-37. DOI: 10.1007/s10804-0139153-y

Robinson, O.C., \& Wright, G.R.T. (2013). The prevalence, types and perceived outcomes of crisis episodes in early adulthood and midlife: A structured retrospectiveautobiographical study. International Journal of Behavioral Development, 37, 407416. DOI: $10.1177 / 0165025413492464$

Robinson, O.C., \& Smith, J.A. (2009). Metaphors and metamorphoses: Narratives of identity during times of crisis. In D. Robinson, P. Fisher, T. Yeadon-Lee, S.J. Robinson \& P. Woodcock (Eds.), Narrative, Memory and Identities (pp.85-94). University of Huddersfield Press.

Robinson, O.C., \& Smith, J.A. (2010). Investigating the form and dynamics of crisis episodes in early adulthood: The application of a composite qualitative method. Qualitative Research in Psychology, 7, 170-191. doi 10.1080/14780880802699084

Ryff, C.D. (1989). Happiness is everything, or is it? Explorations on the meaning of psychological well-being. Journal of Personality and Social Psychology, 57, 106981. doi 10.1037/0022-3514.57.6.1069

Ryff, C. D., \& Heincke, S. G. (1983). Subjective organization of personality in adulthood and aging. Journal of Personality and Social Psychology, 44, 807-816. doi 10.1037/0022-3514.44.4.807

Slaikeu, K.A. (1990). Crisis intervention - a handbook for practice and research. Needham Heights, MA: Allyn and Bacon.

Strauss, A., \& Corbin. J. (1998). Basics of qualitative research: techniques and procedures for developing grounded theory. Thousand Oaks, CA: Sage Publications.

Torges, C.M., Stewart, A.J., \& Duncan, L.E. (2008). Achieving ego integrity: Personality 
development in late midlife. Journal of Research in Personality, 42, 1004-1019. doi 10.1016/j.jrp.2008.02.006

Torges, C.M., Stewart, A.J., \& Duncan, L.E. (2009). Appreciating life’s complexities: Assessing narrative ego integrity in late midlife. Journal of Research in Personality, 43, 66-74. doi 10.1016/j.jrp.2008.12.003

Tornstam, L. (1989). Gero-transcendence theory: A reformulation of the disengagement theory. Aging, 1, 55-63.

Viney, L.L. \& Tych, M. (1985). Content analysis scales: Measuring psychosocial maturity in the elderly. Journal of Personality Assessment, 49, 311-317.

Wagner, K. D., Lorion, R. P., \& Shipley, T. E. (1983). Insomnia and psychosocial crisis: Two studies of Erikson's developmental theory. Journal of Consulting and Clinical Psychology, 51, 595-603. doi 10.1037/0022-006X.51.4.595

Walaskay, M., Whitbourne, S. K., \& Nehrke, M. F. (1983). Construction and validation of an ego integrity status interview. International Journal of Aging and Human Development, 18, 61-72. doi 10.2190/RRAT-BL8J-J2U2-XRD3

Weiss, R.S. \& Bass, S.A. (2002). Introduction. In, R.S. Weiss \& S.A. Bass (Eds.) Challenges of the Third Age: Meaning and purpose in later life (pp.3-12). New York: Oxford University Press.

Wong, J. Y. \& Earl, J. K. (2009). Towards an integrated model of individual, psychosocial, and organizational predictors of retirement adjustment. Journal of Vocational Behavior, 75, 1-13. doi 10.1016/j.jvb.2008.12.010 
Running head: Later-life crisis

Table 1

Participant details - pseudonym, location, sex, pre-retirement profession, current age and age range of crisis

\begin{tabular}{|c|c|c|c|c|c|}
\hline Pseudonym & $\begin{array}{l}\text { Location in } \\
\text { UK }\end{array}$ & Sex & Pre-retirement profession & $\begin{array}{l}\text { Current } \\
\text { age }\end{array}$ & $\begin{array}{l}\text { Age range of crisis } \\
\text { (approx.) }\end{array}$ \\
\hline Anne & Wales & $\mathrm{F}$ & Social worker & 65 & $60-62$ \\
\hline Barbara & Scotland & $\mathrm{F}$ & Accountancy and charity work & 64 & $59-62$ \\
\hline Beatrice & Hampshire & $\mathrm{F}$ & Nurse & 66 & $64-65$ \\
\hline Belinda & Dorset & $\mathrm{F}$ & Secretary & 65 & 60 -present \\
\hline Carolyn & Lancashire & $\mathrm{F}$ & Lab technician & 65 & $59-62$ \\
\hline Diane & Newcastle & $\mathrm{F}$ & Speech and language therapist & 61 & 56-Present \\
\hline Edith & London & $\mathrm{F}$ & Civil servant & 66 & $55-60$ \\
\hline Elizabeth & London & $\mathrm{F}$ & Psychiatric nurse & 68 & $60-66$ \\
\hline Florence & Sheffield & $\mathrm{F}$ & Local councillor & 66 & $60-63$ \\
\hline Hilary & London & $\mathrm{F}$ & Psychotherapist (not retired) & 63 & $60-62$ \\
\hline Jane & Cleveland & $\mathrm{F}$ & $\begin{array}{l}\text { Housing association } \\
\text { administrator }\end{array}$ & 76 & $64-67$ \\
\hline Jenny & Edinburgh & $\mathrm{F}$ & EEG technician & 70 & $61-66$ \\
\hline Paula & Cornwall & $\mathrm{F}$ & Self-employed PA (not retired) & 63 & $59-62$ \\
\hline Barry & Somerset & $\mathrm{M}$ & Electronics engineer & 73 & $65-69$ \\
\hline Brian & Wirral & M & Medical microbiology research & 73 & $59-61$ \\
\hline Edward & Stafford & $\mathrm{M}$ & Prison warden & 63 & $59-63$ \\
\hline Harold & Wales & M & Chemistry lecturer & 71 & $64-67$ \\
\hline Robert & Lincolnshire & $\mathrm{M}$ & $\begin{array}{l}\text { Principal officer in local } \\
\text { government }\end{array}$ & 65 & $60-63$ \\
\hline Steven & London & $\mathrm{M}$ & Materials scientist & 67 & 65-present \\
\hline Ted & Leicester & $\mathrm{M}$ & Art teacher and music director & 69 & $62-66$ \\
\hline Tony & Lancashire & $\mathrm{M}$ & $\begin{array}{l}\text { Butcher, factory manager, } \\
\text { security inspector }\end{array}$ & 69 & $64-67$ \\
\hline
\end{tabular}


Running head: Later-life crisis

Table 2

Loss-inducing stressful life events during crisis episode for each participant, by event type

\begin{tabular}{|c|c|c|c|c|c|c|c|}
\hline & $\begin{array}{l}\text { Illness } \\
\text { in self }\end{array}$ & $\begin{array}{l}\text { Illness in } \\
\text { significant } \\
\text { other }\end{array}$ & $\begin{array}{l}\text { Bereavement } \\
\text { of partner or } \\
\text { parent }\end{array}$ & $\begin{array}{l}\text { Retirement } \\
\text { or being } \\
\text { forced out } \\
\text { of work }\end{array}$ & $\begin{array}{l}\text { Divorce or } \\
\text { relationship } \\
\text { break-up }\end{array}$ & $\begin{array}{l}\text { Moving } \\
\text { house and } \\
\text { geographical } \\
\text { area }\end{array}$ & $\begin{array}{l}\text { No. of } \\
\text { loss- } \\
\text { inducing } \\
\text { events } \\
\text { during } \\
\text { crisis }\end{array}$ \\
\hline Harold & $\mathrm{X}$ & & & $\mathrm{X}$ & $\mathrm{X}$ & $\mathrm{X}$ & 4 \\
\hline Belinda & $\mathrm{X}$ & $\mathrm{X}^{*}$ & & & & $X$ & 3 \\
\hline Diane & $\mathrm{X}$ & $\mathrm{X}^{*}$ & & $\mathrm{X}$ & & $X$ & 4 \\
\hline Tony & $\mathrm{X}$ & $\mathrm{X}$ & $\mathrm{X}$ & $\mathrm{X}$ & & $X$ & 5 \\
\hline Elizabeth & $\mathrm{X}$ & $\mathrm{X}$ & $X$ & $\mathrm{X}$ & & & 4 \\
\hline Edith & & $\mathrm{X}$ & $X$ & $\mathrm{X}$ & & $X$ & 4 \\
\hline Jenny & $\mathrm{X}$ & $\mathrm{X}$ & $\mathrm{X}$ & & & & 3 \\
\hline Edward & $X$ & $\mathrm{X}$ & & $X$ & $X$ & & 4 \\
\hline Steven & $\mathrm{X}$ & $\mathrm{X}$ & $\mathrm{X}$ & & & & 3 \\
\hline Florence & $X$ & $\mathrm{X}$ & $X$ & $\mathrm{X}$ & & & 4 \\
\hline Brian & $\mathrm{X}$ & $\mathrm{X}$ & & $\mathrm{X}$ & & & 3 \\
\hline Hilary & $\mathrm{X}$ & & & $\mathrm{X}$ & & $\mathrm{X}$ & 3 \\
\hline Robert & $\mathrm{X}$ & & & $\mathrm{X}$ & & & 2 \\
\hline Paula & $\mathrm{X}$ & & $\mathrm{X}$ & & & $\mathrm{X}$ & 4 \\
\hline Barry & $X$ & & & $X$ & $X$ & & 3 \\
\hline Anne & $\mathrm{X}$ & & & $\mathrm{X}$ & & & 2 \\
\hline Barbara & & $\mathrm{X}^{*}$ & & $\mathrm{X}$ & & & 2 \\
\hline Jane & $X$ & & $X$ & $\mathrm{X}$ & & $X$ & 4 \\
\hline Carolyn & $\mathrm{X}$ & $\mathrm{X}^{*}$ & $X$ & & & $X$ & 5 \\
\hline Beatrice & & $X$ & $\mathrm{X}$ & $\mathrm{X}$ & & $\mathrm{X}$ & 4 \\
\hline Ted & & & $\mathrm{X}$ & $\mathrm{X}$ & & $\mathrm{X}$ & 3 \\
\hline
\end{tabular}

*Indicates that participant also acted as carer for ill partner or parent 


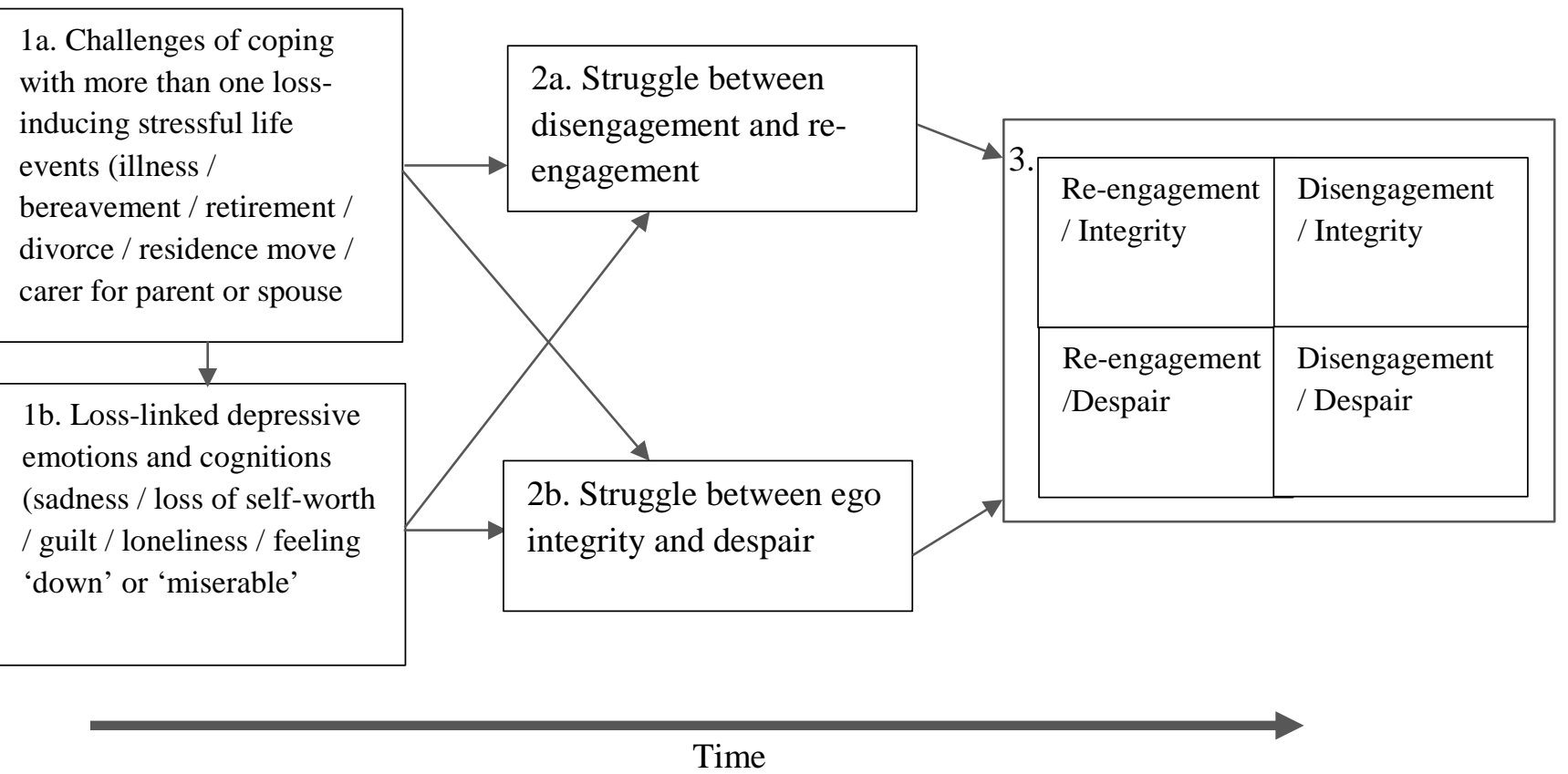

Figure 1. A provisional holistic model of later-life crisis

\footnotetext{
' The concise nature of a journal article means that qualitative findings and example quotes must be reported selectively. This is inevitable given that the interview transcript data upon which this article is based included over 100,000 words in total. We encourage the reader who would like a more comprehensive view of the analysis to contact the corresponding author for the complete Excel table of themes and all supporting quotes.
} 